\title{
PENGARUH PENAMBAHAN TRACE METAL Fe TERHADAP PENYISIHAN KANDUNGAN PADATAN LIMBAH CAIR KELAPA SAWIT MENGGUNAKAN REAKTOR HYBRID UPFLOW ANAEROBIC SLUDGE BLANKET
}

\author{
Julika Sitinjak, Janwarisman Purba, Fatimah \\ Departemen Teknik Kimia, Fakultas Teknik, Universitas Sumatera Utara, \\ Jl. Almamater Kampus USU, Medan 20155, Indonesia \\ Email : julika.sitinjak@yahoo.com
}

\begin{abstract}
Abstrak
Penelitian tentang pengaruh penambahan trace metal Fe terhadap penyisihan kandungan padatan limbah cair kelapa sawit menggunakan Reaktor Hybrid Upflow Anaerobic Sludge Blanket bertujuan untuk mengetahui penambahan trace metal $\mathrm{Fe}$ terhadap penyisihan kandungan padatan limbah cair kelapa sawit menggunakan reaktor HUASB berdasarkan besar penyisihan Chemical Oxygen Demand (COD), Total Suspended Solid (TSS) dan Volatile Suspended Solid (VSS). Reaktor ini merupakan reaktor dengan kombinasi reaktor pertumbuhan tersuspensi di bagian bawah dan reaktor pertumbuhan terlekat di bagian atas. Bahan yang digunakan adalah limbah cair kelapa sawit dan inokulum yang berasal dari PKS Pagar Merbau. Parameter uji yang diamati adalah COD, TSS dan VSS. Kondisi optimum didapat pada beban organik $17024 \mathrm{mg} / \mathrm{l}$ dengan penambahan Fe 0,5 mg/l sehingga diperoleh reduksi COD 85,891\%, reduksi TSS 86,047\% dan reduksi VSS 36,566\%.
\end{abstract}

Kata kunci : inokulum, beban organik, limbah cair kelapa sawit

\begin{abstract}
Research about influence the addition of trace metal Fe against allowance for the solid content of palm oil mill effluent using Hybrid Upflow Anaerobic Sludge Blanket Reactor aim to know the addition of trace metal Fe against allowance for the solid content of palm oil mill effluent using HUASB reactor based on removal of Chemical Oxygen Demand (COD), Total Suspended Solid (TSS) dan Volatile Suspended Solid (VSS). The reactor is a reactor with a combination of suspended growth reactor in the bottom and attached growth reactor at the top. The material used is palm oil mill effluent and inoculum derived from PKS Pagar Merbau. Test parameters to observed are COD, TSS and VSS. The optimum conditions obtained on the organic load is 17024 $\mathrm{mg} / \mathrm{l}$ with the addition of $\mathrm{Fe}$ is $0.5 \mathrm{mg} / \mathrm{l}$ so that obtained COD reduction is $85.891 \%$, TSS reduction is $86.047 \%$ and VSS reduction is $36.566 \%$.
\end{abstract}

Keywords : inoculum, organic load, palm oil mill effluent

\section{Pendahuluan}

Limbah cair kelapa sawit mengandung $\mathrm{COD}=42500 \mathrm{mg} / \mathrm{l}$, BOD $=32000 \mathrm{mg} / \mathrm{l}$ dan $\mathrm{TSS}=16500 \mathrm{mg} / \mathrm{l}$ [9]. Limbah cair tersebut tidak boleh dibuang langsung ke lingkungan karena belum memenuhi baku mutu. Untuk itu perlu dicari salah satu solusi untuk mengolah limbah tersebut. Reaktor HUASB dipilih sebagai salah satu aplikasi. Reaktor Hybrid Upflow Anaerobic Sludge Blanket (HUASB) merupakan kombinasi reaktor pertumbuhan tersuspensi dibagian bawah dengan pertumbuhan terlekat di bagian atasnya. Desain ini memiliki kelebihan dalam mempertahankan konsentrasi biomassa dengan jumlah yang tinggi di dalam reaktor sehingga diharapkan dapat meningkatkan efisiensi pengolahan air buangan.

Dalam reaktor terdapat media melekatnya mikroorganisme, biasanya media pendukung bisa berupa batu, Poli Vinil Chloride (PVC) ataupun bambu. Reaktor ini sangat sesuai dengan iklim
Indonesia yang tropis dan dari segi ekonomis juga menguntungkan sebab biaya operasionalnya relatif rendah jika dibandingkan dengan reaktor aerobik yang memerlukan sistem aerasi. Penambahan trace metal dapat menaikkan persentase penyisihan senyawa organik oleh mikroorganisme [8].

Penggunaan trace metal dalam mengolah limbah cair yang telah pernah dilakukan oleh penelitian sebelumnya, diantaranya adalah :

1. Fatimah, dkk., telah melakukan fermentasi limbah cair kelapa sawit secara anaerobik termofilik dengan waktu tinggal 6 hari dan sistem recycle. Pada penelitian tersebut digunakan trace metal $\mathrm{Ni} 0,49 \mathrm{mg} / \mathrm{l}$, Co 0,42 $\mathrm{mg} / \mathrm{l}$ dan Fe $25 \mathrm{mg} / \mathrm{l}$ dan diperoleh biogas sebanyak 7 - 9 1/hari dan dengan sistem recycle diperoleh laju dekomposisi COD mencapai $85 \%$ [3].

2. Qiang, dkk., juga telah meneliti kebutuhan minimum trace metal pada digester 
anaerobik dari limbah makanan secara mesofilik. Dari penelitian yang mereka lakukan diperoleh konsentrasi yang tepat untuk Fe/COD, Co/COD, dan Ni/COD yaitu $200 \mathrm{mg} / \mathrm{kg}$ COD, $6,0 \mathrm{mg} / \mathrm{kg}$ COD dan 5,7 $\mathrm{mg} / \mathrm{kg}$ COD [6].

Penyisihan kandungan padatan dengan bioreaktor hybrid anaerob juga pernah ditambahkan dalam penelitian pengolahan limbah cair kelapa sawit, diantaranya adalah :

1. Nevolindo, meneliti bahwa penggunaan bioreaktor hybrid anaerob bermedia pelepah sawit dan tandan kosong sawit didapatkan besarnya penyisihan TSS sebesar 81,92\% dan $80,54 \%$ [4].

2. Ahmad, meneliti bahwa penggunaan bioreaktor hybrid anaerob bermedia cangkang sawit didapatkan besarnya penyisihan TSS sebesar $82,78 \%$ pada laju alir 2,8 1/hari [1].

Permasalahan pokok yang akan dijawab dalam penelitian ini adalah bagaimana pengaruh trace metal Fe dalam proses penyisihan senyawa organik limbah cair kelapa sawit menggunakan reaktor HUASB.

\section{Teori}

Berdasarkan sifat tumbuh mikroorganisme dalam reaktor dapat dibedakan atas dua jenis, yaitu: reaktor pertumbuhan tersuspensi dan reaktor pertumbuhan terlekat. Dalam reaktor pertumbuhan tersuspensi, mikroorganisme tumbuh dan berkembang dalam keadaan tersuspensi. Proses lumpur aktif yang banyak dikenal berlangsung dalam reaktor jenis ini. Dalam reaktor pertumbuhan terlekat, mikroorganisme tumbuh di atas media pendukung dengan membentuk lapisan film untuk melekatkan dirinya. Berbagai modifikasi reaktor pertumbuhan terlekat telah banyak dikembangkan selama ini, antara lain: trickling filter, cakram biologi, filter terendam dan reaktor fluidisasi.

Ditinjau dari segi kebutuhan untuk proses penguraian secara biologi, dapat dibedakan juga menjadi dua jenis, yaitu:

1. Proses aerob, yaitu proses yang berlangsung dengan hadirnya oksigen.

2. Proses anaerob, yaitu proses yang berlangsung tanpa oksigen.

Hybrid Upflow Anaerobic Sludge Blanket termasuk ke dalam jenis pertumbuhan tersuspensi dan melekat yang berlangsung tanpa kehadiran oksigen (anaerob). Faktor-faktor penting yang perlu diperhatikan dalam proses pengolahan secara anaerob, yaitu: $\mathrm{pH}$, temperatur, Organic Loading Rate (OLR), padatan tersuspensi, makro dan mikronutrien (trace elements) dan waktu tinggal hidrolik [2].

Hybrid Upflow Anaerobic Sludge Blanket dioperasikan dalam sebuah sistem dimana substrat dialirkan dari bagian bawah reaktor dan keluar dari puncak reaktor setelah melewati unggun (packing). Pertumbuhan tersuspensi terjadi pada bagian bawah reaktor sementara pertumbuhan terlekat berlangsung pada bagian atas reaktor. Salah satu keuntungan reaktor ini adalah berfungsinya fixed bed sebagai filter penahan biomassa dan sebagai media pertumbuhan mikroorganisme [3]. Desain ini memiliki kelebihan dalam mempertahankan konsentrasi biomassa dengan jumlah yang tinggi di dalam reaktor sehingga diharapkan dapat meningkatkan efisiensi pengolahan bahan organik dengan konsentrasi organik tinggi.

Mikroorganisme membutuhkan nutrisi makro dan mikro untuk tumbuh. Kebutuhan nutrisi makro diharapkan dapat tersuplai dari LCPKS, sedangkan nutrisi mikro seperti trace metal disuplai langsung ke dalam reaktor. Trace metal mempunyai peranan penting dalam pertumbuhan mikroorganisme bila sesuai dengan kadar yang dibutuhkan. Trace metal dapat meningkatkan produksi metan yang terjadi pada proses anaerob [3].

\section{Metodologi Penelitian}

Penelitian ini mengenai pengaruh penambahan trace metal Fe dalam proses penyisihan senyawa organik limbah cair kelapa sawit menggunakan reaktor HUASB. Untuk mengetahui pengaruh penambahan trace metal terhadap penyisihan beban organik dilakukan variasi beban organik 15 gr COD/l dan 17 gr $\mathrm{COD} / 1$. Variasi penambahan trace metal $\mathrm{Fe}$ dilakukan $0,3,0,5$ dan $0,7 \mathrm{mg} / \mathrm{l}$.

Parameter analisa dari pengaruh variasi beban organik dan variasi penambahan trace metal adalah COD, TSS dan VSS. Selama proses berlangsung $\mathrm{pH}$ dikontrol, sehingga sesuai dengan pertumbuhan mikroorganisme [1]. Parameter analisa COD dengan menggunakan larutan standar $\mathrm{KMnO}_{4} \quad 0,025 \quad \mathrm{~N}$. Parameter analisa TSS dengan menggunakan oven pada temperatur $103-105{ }^{\circ} \mathrm{C}$ selama 1 jam. Sedangkan parameter analisa VSS dengan menggunakan furnace pada suhu $550{ }^{\circ} \mathrm{C}$ selama 30 menit.

\section{Hasil dan Pembahasan}

Dari hasil pengamatan menunjukkan bahwa dengan penambahan $\mathrm{Fe}$ yang berperan dalam 
pertumbuhan mikroorganisme sehingga dapat menurunkan kandungan COD, TSS dan VSS yang ada dalam sampel limbah. Dimana hal ini untuk menurunkan konsentrasi COD, TSS dan VSS tersebut.

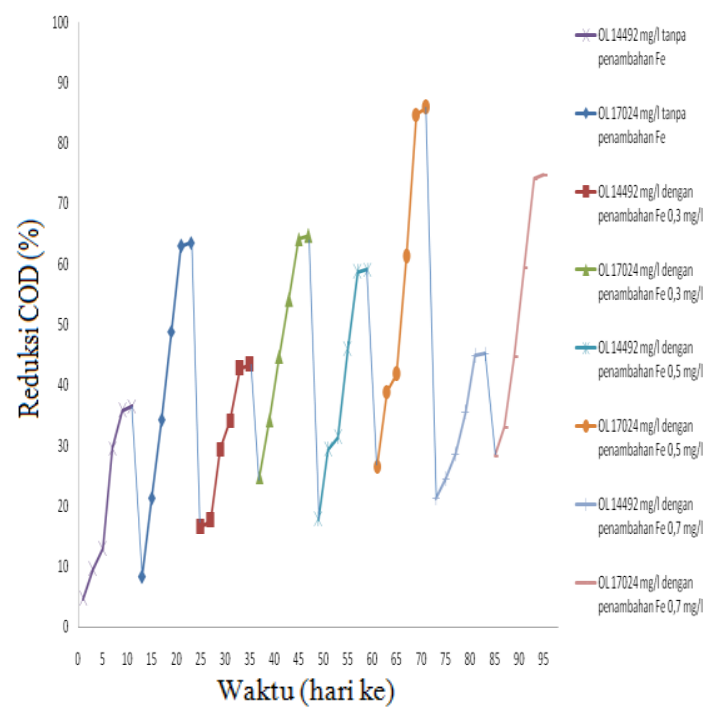

Gambar 1. Pengaruh Waktu Terhadap Reduksi COD Untuk Setiap Variasi Beban Organik Dan Variasi Penambahan Trace Metal Fe.

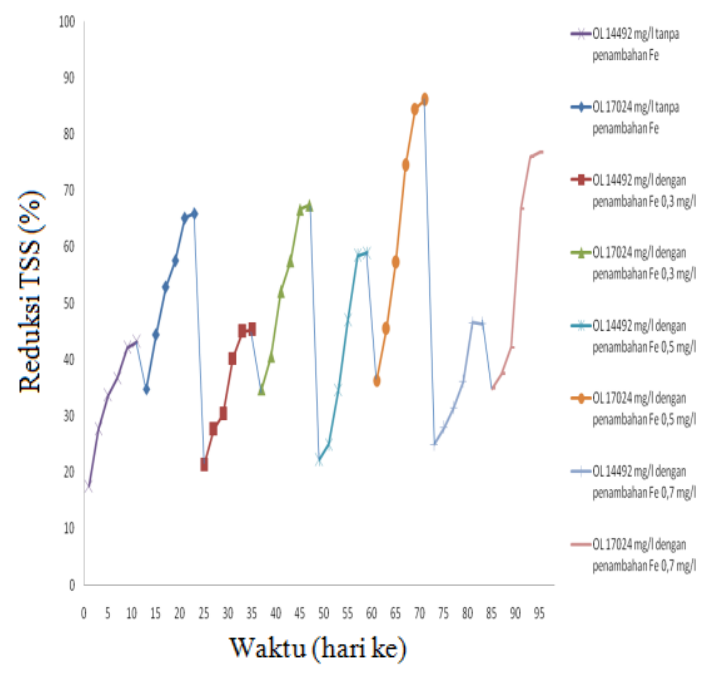

Gambar 2. Pengaruh Waktu Terhadap Reduksi TSS Untuk Setiap Variasi Beban Organik Dan Variasi Penambahan Trace Metal Fe.

Dari hasil pengamatan menunjukkan bahwa dengan penambahan $\mathrm{Fe}$ yang berperan dalam pertumbuhan mikroorganisme sehingga dapat menurunkan kandungan COD, TSS dan VSS yang ada dalam sampel limbah. Dimana hal ini untuk menurunkan konsentrasi COD, TSS dan VSS tersebut. Dari gambar 1, 2 dan 3 menunjukkan bahwa efisiensi penurunan COD,
TSS dan VSS dengan menggunakan $\mathrm{Fe}$ akan meningkat seiring dengan berjalannya waktu yang telah ditentukan.

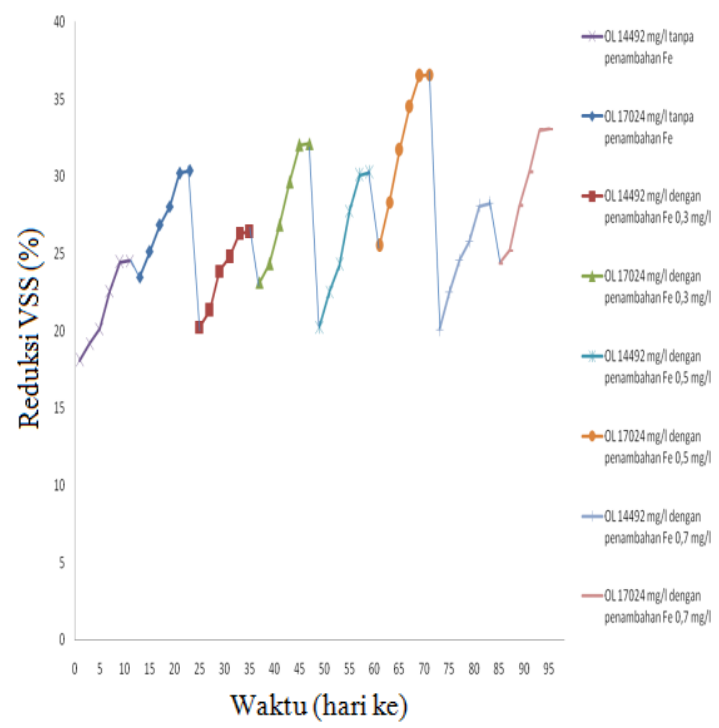

Gambar 3. Pengaruh Waktu Terhadap Reduksi VSS Untuk Setiap Variasi Beban Organik Dan Variasi Penambahan Trace Metal Fe.

Tingginya penurunan konsentrasi COD, TSS dan VSS pada reaktor anaerob disebabkan oleh aktivitas mikroorganisme yang secara alami di dalam air limbah menempel pada media terlekat hingga membentuk lapisan biofilm. Penguraian polutan organik oleh lapisan mikroorganisme akan bertambah secara linier dengan bertambahnya ketebalan biofilm sampai dengan ketebalan peghilangan maksimum tetap konstan dengan bertambahnya ketebalan lebih lanjut [2].

Penurunan konsentrasi COD menandakan senyawa organik yang ada di dalam limbah hampir seluruhnya dapat didegradasi oleh mikroorganisme yang bekerja di dalam bioreaktor hibrid anaerob. Makin lama waktu tinggal akan memberikan waktu kontak antara bahan organik yang terdapat dalam limbah cair dengan mikroorganisme juga semakin lama sehingga degradasi senyawa organik (penurunan COD) menjadi paling besar [7].

Penurunan TSS dan VSS dipengaruhi oleh tertahannya partikel tersuspensi pada media terlekat. Selain itu adanya aliran air limbah dalam reaktor pengolahan menyebabkan terjadinya tabrakan antara partikel tersuspensi hingga membentuk padatan yang lebih besar dan berat sehingga terjadi pengendapan secara alami [5].

Hasil penelitian didapatkan beban organik optimum pada organic loading 17024 mg/l 
dengan penambahan $\mathrm{Fe} 0,5 \mathrm{mg} / \mathrm{l}$ pada hari yang ke-71 dengan reduksi COD $85,891 \%$, reduksi TSS $86,047 \%$ dan reduksi VSS $36,566 \%$.

\section{Kesimpulan}

Dari hasil penelitian didapatkan beban organik optimum pada organic loading 17024 $\mathrm{mg} / \mathrm{l}$ dengan penambahan $\mathrm{Fe} 0,5 \mathrm{mg} / \mathrm{l}$ pada hari yang ke - 71 dengan reduksi COD $85,891 \%$, reduksi TSS 86,047\% dan reduksi VSS 36,566\%.

\section{Daftar Pustaka}

[1] Ahmad, dkk., Penyisihan Kandungan Padatan Limbah Cair Pabrik Kelapa Sawit dengan Bioreaktor Hibrid Anaerob Bermedia Cangkang Sawit, Prosiding Seminar Nasional Fakultas Teknik Universitas Riau, Riau, 2011.

[2] Dartono, dkk., Pengaruh Penambahan Poly Aluminium Chloride (PAC) terhadap Kekeruhan, Warna, dan Total Suspended Solid (TSS) pada Leachate (Air Lindi), TPA Putri Cempo Mojosongo, Surakarta, 2009.

[3] Fatimah, dkk., Pengaruh Pengembalian Lumpur (Recycle Sludge) Terhadap Fermentasi Limbah Cair Pabrik Kelapa Sawit (LCPKS). Prosiding Seminar Nasional Kimia, USU Press. Medan, 2011.

[4] Nevolindo, Penggunaan Bioreaktor Hybrid Anaerob Bermedia Pelepah Sawit Dan Tandan Kosong Sawit, Jurusan Teknik Kimia, Universitas Diponegoro, Semarang, 2010.

[5] Padmono, "Lumpur Aktif: Alternatif Pengolahan Limbah Cair," Jurnal Studi Pembangunan, Kemasyarakatan dan Lingkungan, Vol 1, hal 25-38, 2007.

[6] Qiang, dkk., "Minimum Requirements For Trace Metal In Mesophilic Anaerobic Digester From Foodwaste", Proc. The $4^{\text {th }}$ IWA-ASPIRE Toward Sustainable Water Supply And Recycling Systems, Tokyo, 2011.

[7] Sugiharto, Dasar-dasar Pengolahan Air Limbah, UI Press, Jakarta, 1987.

[8] Yusup, dkk., Peningkatan Efektifitas Pengolahan Air Limbah Proses Pemutihan Pulp dengan Reaktor Up-flow Anaerob Sludge Blanket (UASB) dan Lumpur Aktif Termobilisasi, Berita Selulosa Vol 43, hal 74-82, 2006.

[9] Zinatizadeh, A.A.L., Salamatinia B., Zinatizadeh S.L., Mohamed A.R. and Isa M.H., Palm Oil Mill Effluent Digestion in an Up-Flow Anaerobic Sludge Fixed Flm Bioreactor, 2007. 